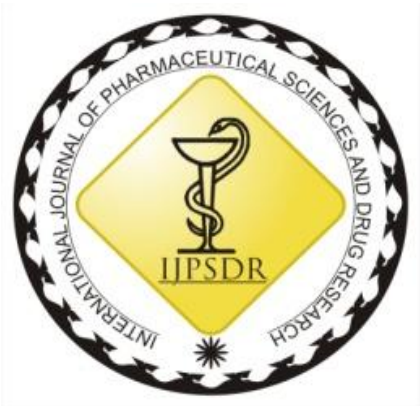

ISSN: 0975-248X

RESEARCH ARTICLE CODEN (USA): IJPSPP (cc) EY-NC-SA

\title{
Development of HPLC Method for Stress Testing of Combination of Two Drugs Using Design of Experiment Concept
}

\author{
Mohini Bajaj, Sanju Nanda* \\ Department of Pharmaceutical Sciences, Maharshi Dayanand University, Rohtak-124 001, Haryana, India
}

Copyright (C) 2019 Mohini Bajaj et al. This is an open access article distributed under the terms of the Creative Commons AttributionNonCommercial-ShareAlike 4.0 International License which allows others to remix, tweak, and build upon the work non-commercially, as long as the author is credited and the new creations are licensed under the identical terms.

\begin{abstract}
This study was conducted to develop, an High Performance Liquid Chromatography using photodiode array detector (HPLC-PDA) method to analyse the samples generated by the stress testing of antifilarial combination (albendazole and diethylcarbamazine citrate) in the solution state. The concept of Quality by Design (Design of Experiment, DoE) approach was used for the development. For the separation of the drugs and its degradation products (DPs), DoE was applied in two stages, i.e., primary parameter stage where factors having major effect were selected. This stage gives us CQA (Critical Quality Attribute) which along with minor factors affecting were varied to get the secondary design. For each of the stage a different design was selected; for primary stage IV optimal design (Response Surface Method) was selected whereas for secondary stage, Taguchi orthogonal array design was selected. The major primary parameters affecting the HPLC method as screened by preliminary studies were the buffer pH, organic modifier (methanol or acetonitrile), initial hold time (start of gradient) and gradient time. The primary stage was completed successfully. The results were compiled in form of resolution of peak from next peak and analysed by DoE. The process fixed the values for buffer $\mathrm{pH}$ (4.38), organic modifier (acetonitrile) and gradient time (30 min). The CQA from primary run was initial hold time. This parameter along with other parameters: initial and final concentration of organic modifier, buffer type (phosphate or acetate), buffer strength (mM) and oven temperature were further varied and samples withdrawn were analysed. The data of secondary design was compiled in the form of resolution (R), analysed by Design Expert and final value for secondary parameter for HPLC method were fixed. The resolution of the peaks for some secondary runs was sufficient reflecting some type of interaction between the drugs and/or degradation products.
\end{abstract}

Keywords: Albendazole, diethylcarbamazine, solution-state stability, HPLC, stress testing.

DOI: 10.25004/IJPSDR.2019.110611

Int. J. Pharm. Sci. Drug Res. 2019; 11(6): 347-353

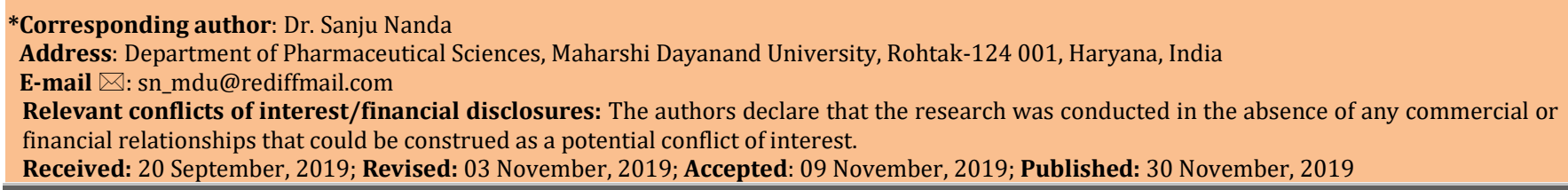

\section{INTRODUCTION}

The drugs selected are from the drugs categorised under the group of infectious diseases termed "Neglected Tropical Diseases" (NTD). ${ }^{[1]}$ These diseases are predominantly found in low- income population of most of the developing countries. The regions of highest prevalence of these diseases are mostly tropical and subtropical areas of African, Asian, as well as 
American continents. The major concern of these diseases is the presence of multiple infections leading to severe pain may/may not be followed by permanent disability and even leading to death. [1] The other major drawback is disfigurement which leads to social stigma, especially for females. [1] The drugs belong to category of antifilarial drugs. [1-3] The drug for treatment and dosage regimen for these diseases was not systemized and many different regimens were followed. So, World Health Organisation (WHO) in 2017 issued, "Guideline for Alternative Mass Drug Administration Regimen to Eliminate Lymphatic Filariasis". ${ }^{[4]}$ Filariasis (lymphatic dwelling filariae) is infection caused by nematodes (worms) belonging to family Filarioidea. The class encompasses organisms Wuchereria banocrofti (90\%), Burgia malayi and Burgia timori. The two eye infections caused by Loa loa and Onchocerca volvulus (river blindness) are also included. [1-2] The drug combination albendazole and diethylcarbamazine is one of the recommendations for filariasis when it is not co-endemic with eye infections. [3] The structures of both the drugs are shown in Fig. 1. [5-6]
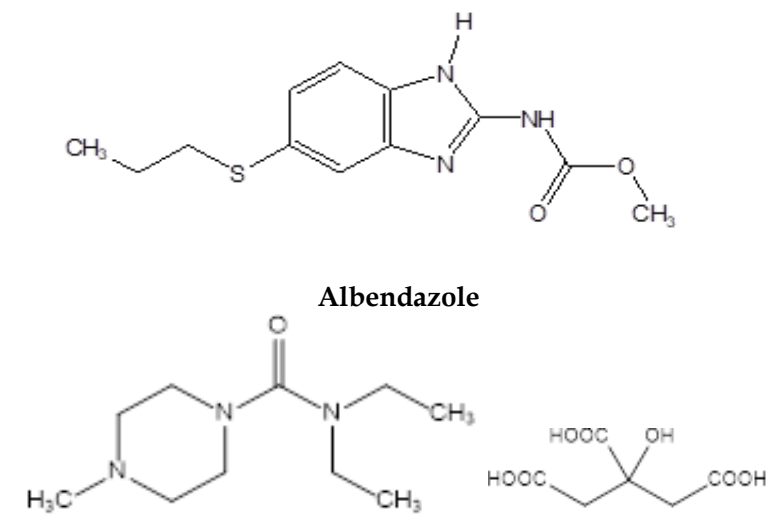

Diethylcarbamazine citrate

Fig. 1: Structures of the two drugs

According to ICH Q 1 A (R2) [7] guidelines on "Stability Testing of New Drug Substances and Products", stress testing is defined as "Stress testing of the drug substance can help identify the likely degradation products, which can in turn help establish the degradation pathways and the intrinsic stability of the molecule and validate the stability indicating power of the analytical procedures used. The nature of the stress testing will depend on the individual drug substance and the type of drug product involved." These studies are very useful to finalize storage conditions as well as the manufacturing conditions of drug or its combinations. They are also helpful in selecting excipients to be used in the manufacture of dosage forms. The drugs are put on stress testing (forced degradation) studies by exposure to extremes of hydrolytic (at different $\mathrm{pH}$ ), light and oxidative conditions. [8-12]

The analytical method for the drug combination of albendazole (ALB) and diethylcarbamazine (DEC) and separation of their degradation products is not well documented in literature, only some studies giving the stability indicating assay for the drugs are available. Keeping all the above in mind, this study was planned for development of method of analysis using HPLCPDA. The stress conditions selected were hydrolytic (acidic, basic and neutral) and oxidative stress using hydrogen peroxide as reagent. The DoE concept was only applied to analytical method but not the stress conditions as highlighted in many publications. [13-19]

\section{Materials and Methods \\ Drugs and reagents}

Pure albendazole (ALB) and diethylcarbamazine (DEC) were obtained from Mahalaxmi Chemicals (Hyderabad, India). Analytical reagent (AR) grade sodium hydroxide $(\mathrm{NaOH})$ and hydrochloric acid $(\mathrm{HCl})$ were purchased from LOBA Chemie Pvt. Ltd. (Mumbai, India), hydrogen peroxide $\left(\mathrm{H}_{2} \mathrm{O}_{2}\right)$ from S.D. fine-chem Ltd. Boisar, India). Buffer salts and all other chemicals of AR grade were bought from local suppliers. HPLC grade acetonitrile $(\mathrm{ACN})$ and methanol $(\mathrm{MeOH})$ were procured from Fischer Scientific (Mumbai, India). HPLC grade water for studies was obtained from water purification unit (Milli-Q, Millipore Corporation, Germany).

\section{Apparatus and equipment}

Separation behaviour of the drugs and their degradation products formed were studied using a Agilent LC liquid chromatography system that was equipped with a photodiode detector (1260 DAD VL), and was controlled by EZ chrome Elite software, version 3 (all from Agilent, Germany). The column used was Inertsil ODS-3 C-18 $(250 \mathrm{~nm} \times 4.6 \mathrm{~nm}$, i.d., particle size $5 \mu$ ).

Precision water bath equipped with MV controller (Julabo, Seelbach, Germany was used for generating samples for solution degradation studies. A pH/Ion analyzer (Seven Easy, Mettler Toledo, Schwerzenbach, Switzerland) was used adjust the $\mathrm{pH}$ of buffer solutions. Other small equipment used was sonicator (YJ 5200 DT, Citizen Scale India Pvt. Ltd., India), precision analytical balance (XP 205 and AG204, Mettler Toledo, Schwerzenbach, Switzerland) and autopipettes (Eppendorf, Hamburg, Germany).

Solution-state stress studies

The degradation studies were conducted for the hydrolytic stress under acidic $(1 \mathrm{~N} \mathrm{HCl})$, basic $(1 \mathrm{~N}$ $\mathrm{NaOH}$ ) and neutral (50:50, $\mathrm{ACN}: \mathrm{H}_{2} \mathrm{O}$ ) according to the conditions stated in table 1 and for oxidative stress two concentrations of $\mathrm{H}_{2} \mathrm{O}_{2}$ (5\% and $\left.15 \%\right)$ were selected. [3,910] The solution of both the drugs was prepared at 2 $\mathrm{mg} / \mathrm{ml}$. For the individual drug studies, the volume of $25 \mathrm{ml}$ was drawn of the drug and was mixed with $25 \mathrm{ml}$ of the stressor. In case of combination, the individual drug volume of $12.5 \mathrm{ml}$ was withdrawn, mixed and then added $25 \mathrm{ml}$ of the stressor to the mixture. [17-19] Studies were carried on the solution where the stressor drugs and stressor concentration was in the ratio of 1:1. All the samples were maintained at $80^{\circ} \mathrm{C}$ for the period 
of the study. The sample of $3 \mathrm{ml}$ was withdrawn after fixed intervals. Replicates of all the possible sets were also prepared and simultaneously subjected to same study conditions.

\section{Preparation of samples for HPLC analyses}

The samples withdrawn were diluted with equal amount of diluent. The final sample of each study condition were mixed and then diluted further to get concentration of $1 \mathrm{mg} / \mathrm{ml}$. All the final generated samples were filtered through $0.22 \mu$ membrane filter before injecting in HPLC system.

Method development and optimization

The forced degraded sample solutions were preliminary screened for degradation behaviour. After the initial screening, the samples parametersconcentration of stressor, time period of study- were finalized. This also gave us knowledge regarding HPLC parameters effects. The finalized samples were then subjected to DoE. The number of runs and parameters for each run were calculated from the Design expert software (trial version 9). The limit for variable primary run parameters selected (organic modifier, buffer $\mathrm{pH}$, initial hold time, gradient time) [2023] are shown in table 3 . The suggested 32 runs were determined using IV optimal design. The actual run details of variable parameters were as shown under factors heading in table 6 . The fixed parameters were initial organic modifier, final organic modifier, flow rate, buffer type, buffer strength, injection volume and oven temperature the detail is given in table 2. [24-27] All the analysis were performed using PDA detector and the wavelength finally selected was $220 \mathrm{~nm}$ for DEC and all its combinations.

The compilation of results and statistical treatment of data obtained from study of primary run were done. The results were analysed, and the parameters optimized for this primary stage were $\mathrm{pH}$ of the buffer, gradient time, organic modifier concentration and initial hold time. These parameters were used as fixed parameters in secondary run and other parameters varied in the secondary design are as compiled in table 4. The initial hold time was identified as CQA which was further again studied in secondary stage. The seven parameters selected were subjected to Taguchi orthogonal design and the runs are as compiled in table 5 . The samples were subjected to the runs of secondary study and the results obtained were compiled and subjected to DoE.

\section{RESULTS}

The results of samples subjected to chromatographic study for preliminary screening were the basis for subsequent selection of parameters for primary selection as well as secondary screening. The parameters detailed in table 2 were the parameters most affecting the method development. So, they were selected for primary and secondary based on major or minor effects. The summary of all the run for primary parameters and resolution (R) of peak from next peak in each run are enumerated in table 6. The overlay chromatograms of the some of the runs are also shown in fig. 2. The data obtained was subjected to analysis and evaluation by Design Expert software and results obtained are shown in fig. 3 . The optimized condition for primary parameters were buffer $\mathrm{pH}$ at 4.38 , gradient time to be $30 \mathrm{~min}$, ratio of organic modifier $\mathrm{ACN}: \mathrm{MeOH} ; 100: 0$, and initial hold time for the method being $0 \mathrm{~min}$.

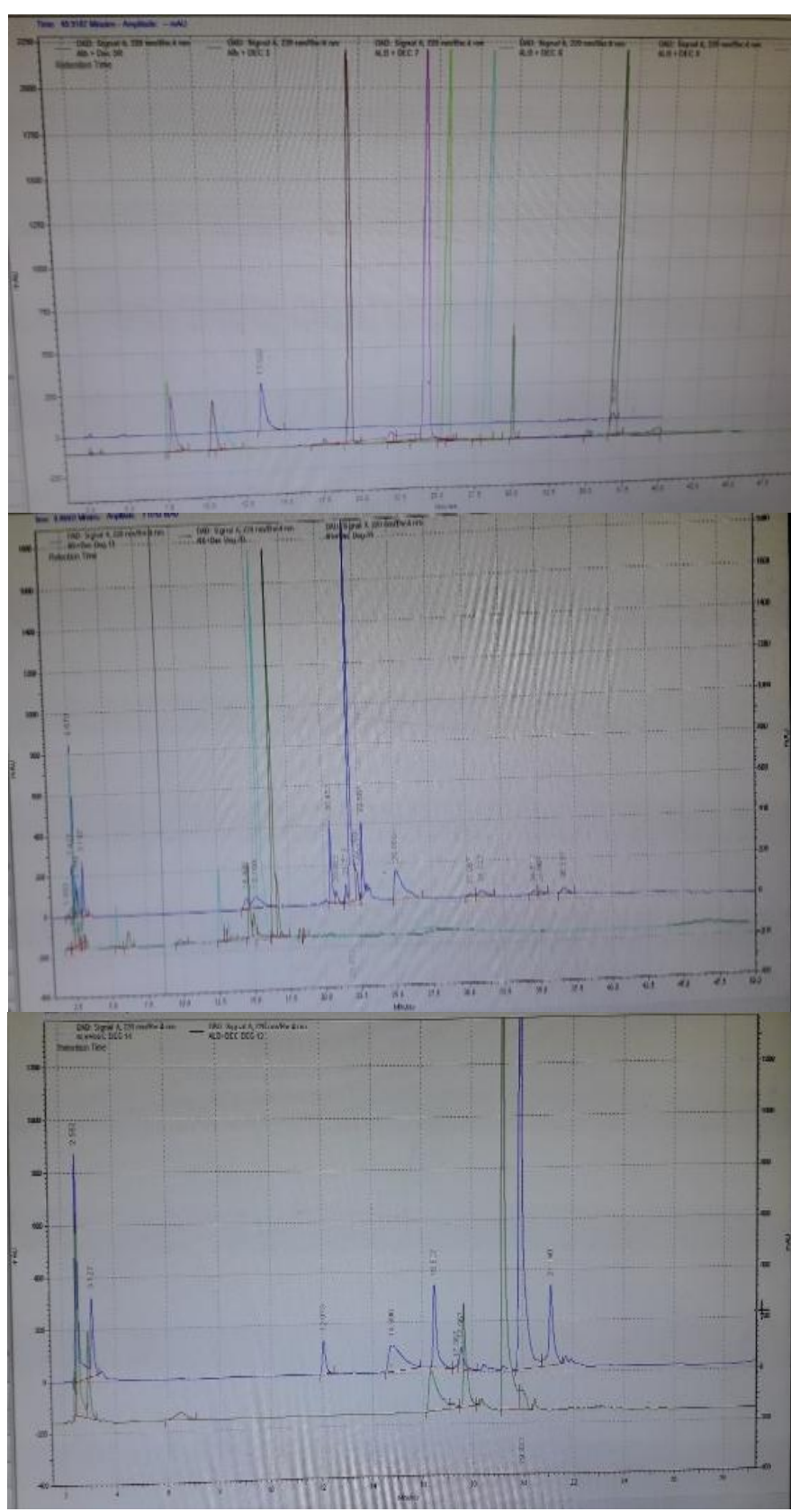

Fig. 2: Primary screening data showing overlay chromatograms of some of the runs of ALB+DEC combination.

Table 1: Levels of forced degradation parameters used for optimization of hydrolytic and oxidative conditions.

\begin{tabular}{cccc}
\hline Conditions & Stressor & Concentration & Temperature $\left({ }^{\circ} \mathrm{C}\right)$ \\
\hline Hydrolytic & $\mathrm{HCl}$ & $1 \mathrm{~N}$ & 80 \\
& $\mathrm{NaOH}$ & $1 \mathrm{~N}$ & 80 \\
& $\mathrm{ACN}: \mathrm{H}_{2} \mathrm{O}$ & $50: 50, \mathrm{v} / \mathrm{v}$ & 80 \\
Oxidative & $\mathrm{H}_{2} \mathrm{O}_{2}$ & $5 \%$ and $15 \%$ & 80 \\
\hline
\end{tabular}


Mohini Bajaj et al. / Development of HPLC Method for Stress Testing of Combination of Two Drugs

Table 2: Selected primary and secondary parameters and then optimization for analytical methodology using various experimental designs.

\begin{tabular}{|c|c|c|}
\hline $\begin{array}{l}\text { Input method } \\
\text { parameters }\end{array}$ & $\begin{array}{c}\text { Primary parameter } \\
\text { selection (IV-optimal } \\
\text { design) }\end{array}$ & $\begin{array}{l}\text { Secondary parameter } \\
\text { screening (Taguchi } \\
\text { orthogonal array) }\end{array}$ \\
\hline $\begin{array}{l}\text { Organic Modifier } \\
\text { (ACN: } \mathrm{MeOH} \text { ) }\end{array}$ & $\begin{array}{c}100: 0,50: 50 \text { and } \\
0: 100\end{array}$ & $100: 0^{*}$ \\
\hline Buffer $\mathrm{pH}$ & $3-7$ & $4.38^{*}$ \\
\hline Gradient time & $20-40 \mathrm{~min}$ & $30 \mathrm{~min}^{*}$ \\
\hline Initial hold time & 0,5 and $10 \mathrm{~min}$ & $0 \min ^{*}$ \\
\hline $\begin{array}{c}\text { Initial organic } \\
\text { modifier }\end{array}$ & $5 \% *$ & 2 and $8 \%$ \\
\hline $\begin{array}{l}\text { Final organic } \\
\text { modifier }\end{array}$ & $75 \%$ * & 60 and $80 \%$ \\
\hline Flow rate & $1.0 \mathrm{ml} / \mathrm{min}^{*}$ & 0.5 and $1.0 \mathrm{ml} / \mathrm{min}$ \\
\hline Buffer type & Phosphate* & Phosphate and acetate \\
\hline Buffer strength & $10 \mathrm{mM}^{*}$ & 8 and $12 \mathrm{mM}$ \\
\hline Injection volume & $10 \mu 1^{*}$ & 5 and $15 \mu l$ \\
\hline Oven temperature & $30^{\circ} \mathrm{C}^{*}$ & 30 and $35^{\circ} \mathrm{C}$ \\
\hline
\end{tabular}

Table 3: Design Summary for primary parameters selection.

File Version
Response Surface
Design type
Design model
Runs

Build time (ms)

\begin{tabular}{cc} 
Table 4: Design summary for secondary parameter screening. \\
\hline File Version & 9.0 .6 .2 \\
Design type & Taguchi OA \\
Study type & Coordinate exchange \\
Design model & Factorial \\
Runs & Main effect \\
Build time (ms) & 8 \\
& 1.00 \\
\hline
\end{tabular}

Table 5: Variable parameters selected for secondary studies.

\begin{tabular}{|c|c|c|c|c|c|c|c|}
\hline Method & $\begin{array}{c}\text { Initial organic } \\
\text { modifier }(\%)\end{array}$ & $\begin{array}{l}\text { Final organic } \\
\text { modifier }(\%)\end{array}$ & $\begin{array}{c}\text { Injection } \\
\text { Volume }(\mu \mathrm{L}) \\
\end{array}$ & Buffer Type & $\begin{array}{c}\text { Buffer } \\
\text { strength }(\mathrm{mM})\end{array}$ & $\begin{array}{c}\text { Initial hold } \\
\text { time (min) }\end{array}$ & $\begin{array}{c}\text { Oven temperature } \\
\left({ }^{\circ} \mathrm{C}\right)\end{array}$ \\
\hline Sec1 & 8 & 60 & 1 & Acetate & 8 & 15 & 25 \\
\hline Sec2 & 8 & 90 & 0.5 & Acetate & 8 & 5 & 35 \\
\hline Sec3 & 2 & 90 & 1 & Acetate & 12 & 5 & 25 \\
\hline Sec4 & 2 & 60 & 0.5 & Acetate & 12 & 15 & 35 \\
\hline Sec5 & 2 & 60 & 0.5 & Phosphate & 8 & 5 & 25 \\
\hline Sec6 & 2 & 90 & 1 & Phosphate & 8 & 15 & 35 \\
\hline Sec7 & 8 & 90 & 0.5 & Phosphate & 12 & 15 & 25 \\
\hline Sec8 & 8 & 60 & 1 & Phosphate & 12 & 5 & 35 \\
\hline
\end{tabular}

Table 6: Variable parameters selected for primary studies.

\begin{tabular}{|c|c|c|c|c|c|c|c|c|c|c|c|c|c|c|c|}
\hline \multirow[b]{2}{*}{ Run } & \multicolumn{4}{|c|}{ Variable factor } & \multicolumn{11}{|c|}{ Responses } \\
\hline & $\begin{array}{c}\text { Buffer } \\
\text { pH }\end{array}$ & $\begin{array}{c}\text { Gradie } \\
\text { nt Time } \\
\text { (Min) }\end{array}$ & $\begin{array}{c}\text { ACN: } \\
\text { MeOH } \\
(\%)\end{array}$ & $\begin{array}{l}\text { Initial } \\
\text { Hold } \\
\text { time } \\
\text { (Min) }\end{array}$ & $\mathbf{R} 1$ & $\mathbf{R} 2$ & $\mathbf{R} 3$ & R4 & R5 & R6 & R7 & R8 & R9 & R10 & R11 \\
\hline 1 & 3 & 20 & $0: 100$ & 10 & 0 & 0 & 0 & 0.78 & 0.95 & 0 & 0 & 0 & 0 & 0 & 0 \\
\hline 2 & 7 & 26.7 & 100:0 & 0 & & & & & & & & & & & \\
\hline 3 & 7 & 20 & $50: 50$ & 0 & 0 & 2.39 & 2.5 & 6.63 & -4.78 & 5.88 & 0 & 2.94 & 6.47 & 0 & 0 \\
\hline 4 & 7 & 40 & 100:0 & 10 & & 2.95 & 2.7 & 2.03 & 0 & 1.25 & 0 & 7.69 & 4.47 & 4.91 & 0 \\
\hline 5 & 4.5 & 31 & $50: 50$ & 5 & 0 & 2.19 & 1.55 & 2.17 & 0 & 1.98 & 0 & 1.89 & 1.72 & 3.06 & 0 \\
\hline 6 & 7 & 40 & $0: 100$ & 5 & & 3.1 & 23.06 & 4.33 & 0.09 & 8.22 & 0 & 2.66 & 2.19 & 0 & 2.76 \\
\hline 7 & 4.5 & 22.9 & $50: 50$ & 0 & 0 & 2.38 & 2.48 & 5.72 & 4.26 & 4.26 & 5.69 & 0 & 2.94 & 7.39 & 0 \\
\hline 8 & 5 & 20 & 100:0 & 10 & 0 & 1.12 & 0 & 14.18 & 3.04 & 3.42 & 0 & 4.58 & 5.29 & 0 & 7.09 \\
\hline 9 & 6.1 & 33.3 & $50: 50$ & 0 & 0 & 2.51 & 1.23 & 0 & 3.61 & 26.29 & 39.75 & 4.95 & 3.54 & 0 & 9.89 \\
\hline 10 & 3 & 40 & 100:0 & 0 & 0 & 2.44 & 2.67 & 14.25 & 0 & 0 & 57.05 & 0 & 1.49 & 7.41 & 0 \\
\hline 11 & 7 & 26.7 & $50: 50$ & 10 & 1.2 & 0 & 2.77 & 0 & 0 & 15.58 & 36.56 & 0 & 1.2 & 7.6 & 0 \\
\hline 12 & 7 & 26.7 & 100:0 & 0 & -1.25 & 2.96 & 15.1 & 0 & 36.2 & 0 & 3 & 1.24 & 7.57 & 0 & 0 \\
\hline 13 & 3 & 20 & 0:100 & 0 & 1.15 & 2.76 & 3.14 & 13.17 & 1.61 & 6.16 & 2.65 & 1.61 & 11.56 & 4.83 & 1.62 \\
\hline 14 & 3 & 20 & 100:0 & 5 & 0 & 2.4 & 2.51 & 5.24 & 8.87 & 3.65 & 4.13 & 1.59 & 7.14 & 1.3 & 4.93 \\
\hline 15 & 4.5 & 31 & $0: 100$ & 0 & 0 & 2.68 & 1.32 & 15.32 & -27.1 & 2.27 & 0 & 9.33 & 0 & 1.53 & 3.8 \\
\hline 16 & 3 & 33.3 & 100:0 & 10 & 0 & 0 & 2.01 & -4.89 & 0 & 15.05 & 7.49 & 1.64 & 5.26 & 2.44 & 0 \\
\hline 17 & 3 & 40 & 0:100 & 5 & -1.18 & 1.69 & 3.26 & 0 & 4.63 & 1.4 & 0 & 5.74 & 13.85 & 0 & -0.39 \\
\hline 18 & 3 & 20 & $50: 50$ & 5 & 0 & 3.64 & 4.51 & 2.35 & 20.64 & -6.74 & 4.58 & 0 & 6.91 & 0 & 0 \\
\hline 19 & 5 & 40 & 100:0 & 5 & 0 & 1.15 & 2.91 & 7.22 & 8.22 & 5.46 & 0 & 2.21 & 17.37 & 1.25 & 5.46 \\
\hline 20 & 7 & 20 & 100:0 & 5 & -1.2 & -2.81 & 3.2 & 0 & 0 & 12.06 & 12.13 & 1.51 & 5.62 & 0 & 0 \\
\hline 23 & 7 & 20 & $0: 100$ & 10 & 2.79 & 1.18 & 0 & -3.95 & 0 & 8.72 & 0 & 1.68 & 0 & 1.89 & 0 \\
\hline 26 & 3 & 40 & $50: 50$ & 10 & 0 & 1.19 & 16.86 & 8.1 & 0 & 8.1 & 11.04 & 0 & 1.46 & 2.47 & 0 \\
\hline 28 & 5 & 20 & $0: 100$ & 5 & 0 & 3.8 & 47.78 & 4.73 & 0 & 2.92 & 0 & 4.53 & 9.47 & 0 & 4.5 \\
\hline 29 & 7 & 40 & $50: 50$ & 5 & 2.44 & 3.45 & 21.22 & 21.22 & 0 & 31.15 & 0 & 1.61 & 6.3 & 2.48 & 0 \\
\hline 30 & 3 & 34.1 & $50: 50$ & 0 & 0 & 1.93 & 5.88 & 13.1 & 0.91 & 0 & 0 & 0 & 0 & 0 & 11.98 \\
\hline 31 & 5 & 40 & $0: 100$ & 10 & 0 & 3.65 & 48.87 & 5.31 & 0 & 3.34 & 0 & 4.98 & 11.99 & 0 & 6.04 \\
\hline 32 & 7 & 40 & 0:100 & 0 & 0 & 4.96 & 26.67 & 0 & 0 & 41.1 & 0 & 4.27 & 4.59 & 0 & 7.42 \\
\hline
\end{tabular}

The optimized conditions were fixed parameters for secondary studies except hold time which needed to be further varied along with other parameters as given in table 2 . The results of secondary run were compiled in table 7 and the chromatograms are shown in fig. 4 . The chromatograms of all the 8 runs are shown in fig. 4 where the upper curve shows the chromatogram of the pure drug combination followed by their stressed 
Mohini Bajaj et al. / Development of HPLC Method for Stress Testing of Combination of Two Drugs.

sample chromatogram at same run condition. PDA detector screening chromatogram for one of the run is

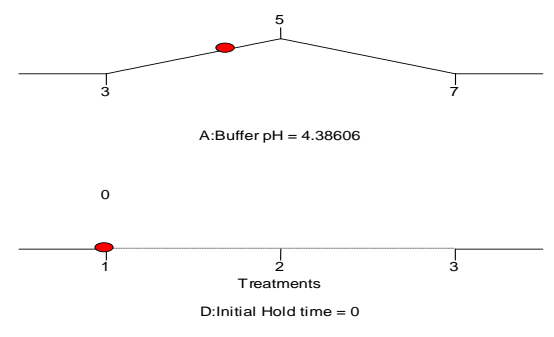

shown in fig. 5 .

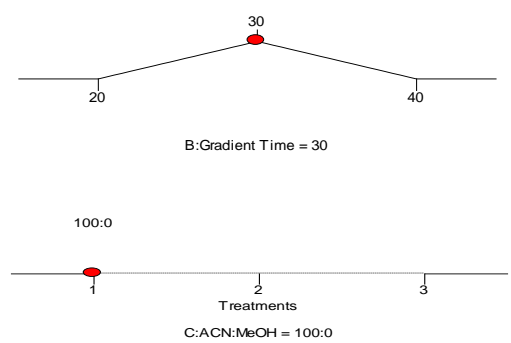

Fig. 3: Finalised condition of variable parameters from the primary screening from compiled data and after analysis by DoE.
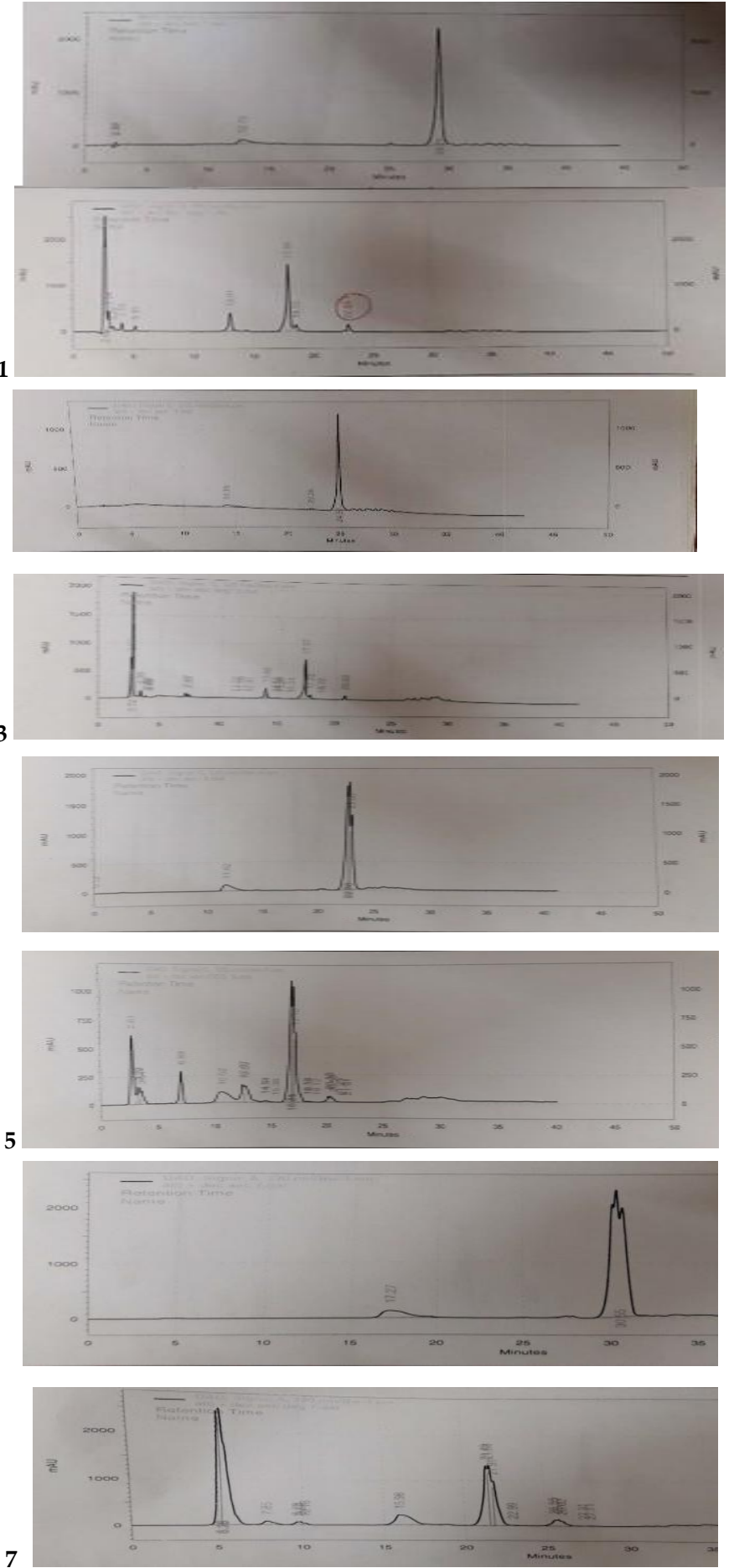

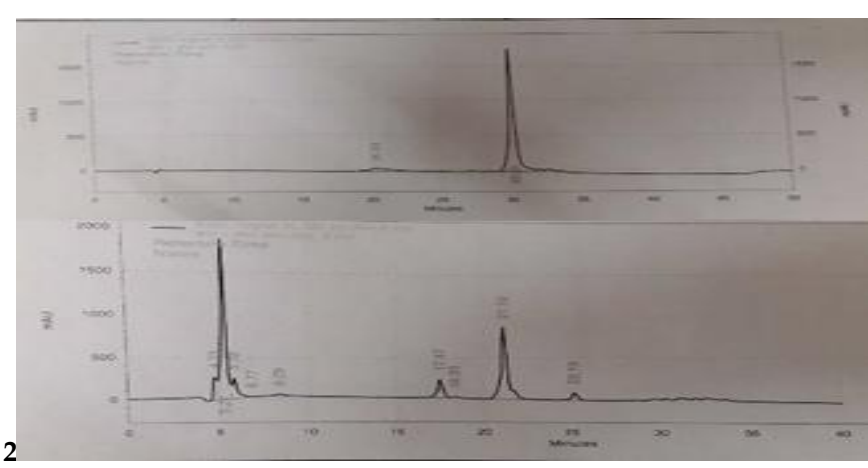

2
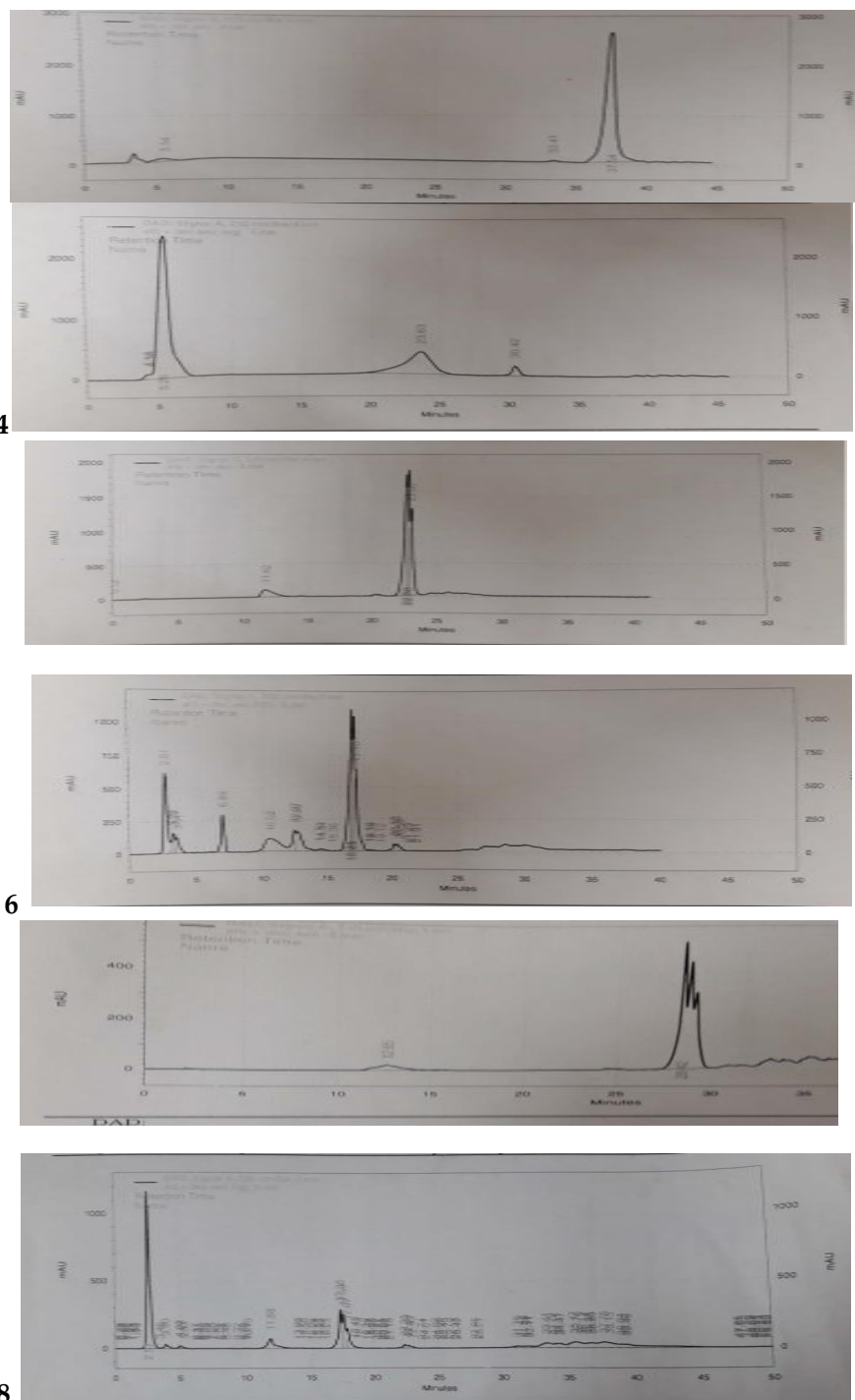

8

Fig. 4: Secondary run chromatograms for all the 8 runs (1-8) as given detailed in table 5 . The data is aligned with the combination (ALB+DEC pure drugs) run on top and that of the stressed samples below it. 


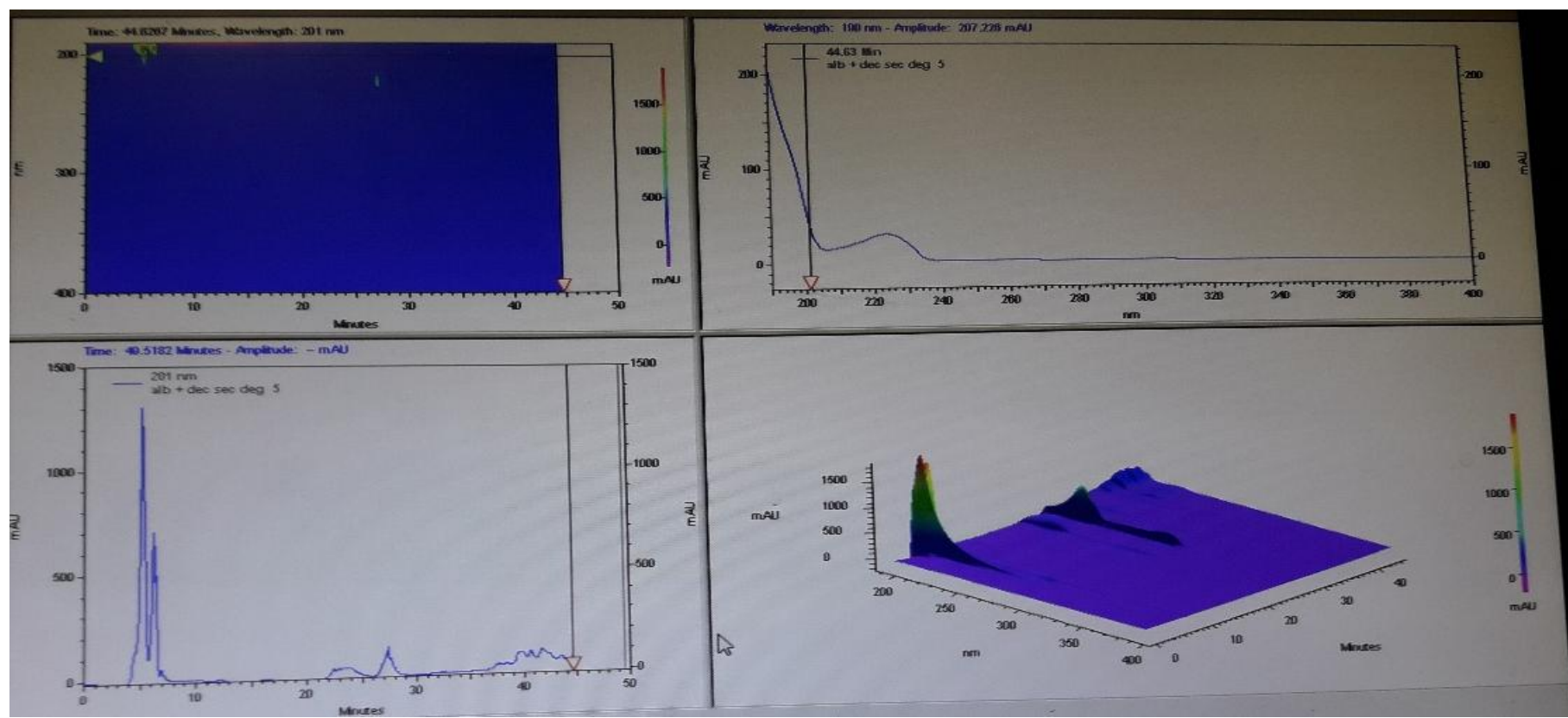

Fig. 5: Data showing the PDA detector screening data for one of the secondary screening run of ALB + DEC combination.

Table 7: Compiled results of secondary runs showing the resolution of peak relative to next adjacent peaks.

\begin{tabular}{cccccccccccc}
\hline Run & R1 & R2 & R3 & R4 & R5 & R6 & R7 & R8 & R9 & R10 & R11 \\
\hline Sec1 & 0 & 4 & 3 & 2 & 1 & 4 & 6 & 7 & 0 & 5 & 9 \\
Sec2 & 0 & 5 & 4 & 2 & 2 & 7 & 8 & 9 & 8 & 9 & 0 \\
Sec 3 & 0 & 7 & 1 & 7 & 8 & 9 & 7 & & 9 & 8 & 7 \\
Sec 4 & 0 & 6 & 5 & 7 & 8 & 7 & 9 & 7 & 5 & 5 & 4 \\
Sec 5 & 0 & 8 & 8 & 6 & 5 & 6 & 5 & 9 & 7 & 4 & 3 \\
Sec 6 & 0 & 6 & 4 & 5 & 2 & 5 & 8 & 9 & 9 & 7 & 3 \\
Sec 7 & 0 & 5 & 6 & 4 & 1 & 4 & 9 & 3 & 6 & 9 & 7 \\
Sec 8 & 0 & 4 & 8 & 3 & 4 & 9 & 6 & 4 & 3 & 6 & 9 \\
\hline
\end{tabular}

The HPLC secondary studies data was compiled and further analyzed by the Design Expert software to get the optimization parameters (fig. 6). The Initial organic modifier at $8 \%$, final organic modifier at $80 \%$, flow rate of $1.0 \mathrm{ml}$ was the optimized condition for the first three varied factors. The buffer type optimized was acetate buffer, helpful when further doing LC-MS studies. The strength of the buffer finalized was $12 \mathrm{mM}$ selected from $8 \mathrm{mM}$ and $10 \mathrm{mM}$. The oven temperature also affected the resolution, so it was finalized at $35^{\circ} \mathrm{C}$.

\section{DISCUSSION}

Systematic forced degradation studies on combination of albendazole and diethylcarbamazine were performed keeping in mind the various guidelines already discussed namely ICH Q1A(R2) guideline, WHO guidelines. [7-8, 27] An HPLC with PDA detector method was developed using DoE, for best results many of the effectors of performance were evaluated. DoE was applied in two stages as if method was developed in one stage would lead a method which will a huge number of parameters which will be tough to handle. Some to divide it method was developed in two stages, primary for selection of parameters and secondary for screening. [17]

The design applied was under category RSM (response surface methodology) while for secondary stage was orthogonal array design. The number of runs in primary was 32, in some of runs the peaks were exchanged so a negative sign was put and for some peak it was not resolved so a 0 . The first peak was taken as 0 but where it was exchanged a negative value.
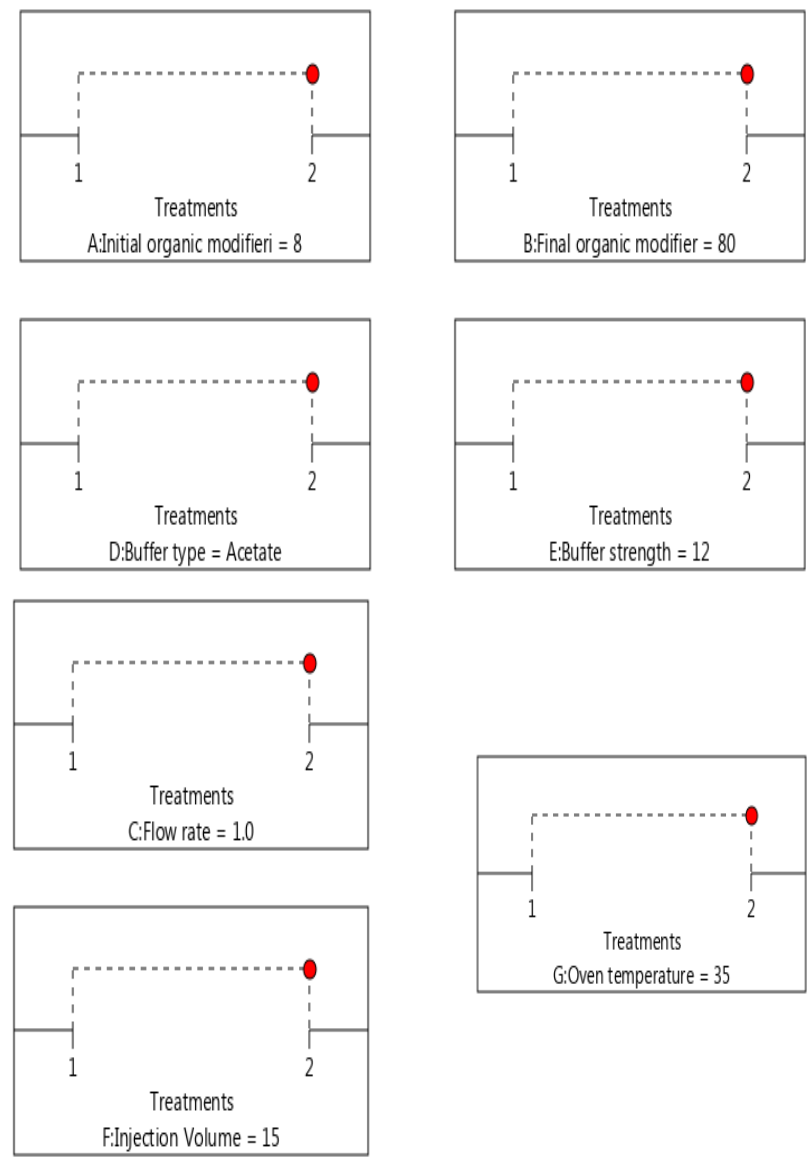

Fig. 6: Results of analysis of secondary data by DoE software and the optimised conditions from 8 runs.

The overlay chromatogram of primary peak highlighted that most of peak were well resolved and first three peaks were much affected by change in chromatographic conditions. ${ }^{[20]}$ These peaks can be due 
to $\mathrm{H}_{2} \mathrm{O}_{2}$ and citrate salt which is salt form of diethylcarbamazine. There are chances that the salt can under harsher conditions react with DEC or may be ALB leading to formation of some of the degradation products, that so under particular conditions. The will lead to variation in the peak and some interactions. As per the reported literature and its metabolism albendazole is more prone to oxidation. [5] There are reported literatures of formation of disulphide bond [28] as well as hydrazide bond [29] under some conditions. This is the possibility in albendazole.

The final method was optimized using acetate buffer in the mobile phase, so that this method can be extended to mass systems when and if need arise. This can be helpful technique for the characterisation of the DPs.

\section{REFERENCES}

1. World Health Organisation. First WHO report on neglected tropical diseases. Geneva, 2010.

2. Lemk TL. Antiparasitic Agent. In: Thomas L. Lemke, editor. Foye's Principles of Medicinal Chemistry. Seventh ed. USA: Lippincott Williams \& Wilkins; 2008. p. 1146-50.

3. Department of Control of Neglected Tropical Diseases (NTD). Preventive chemotherapy in human helminthiasis: coordinated use of anthelminthic drugs in control interventions: a manual for health professionals and programme managers. Geneva: 2006.

4. World Health Organisation. Alternating mass drug administration regimens to eliminate lymphatic filariasis. Geneva, 2017, p. 1-47.

5. Council of Europe. European Pharmacopoeia. Ninth ed Strasbourg: Council of Europe; 2016. p. 1657-8.

6. Council of Europe. European Pharmacopoeia. Ninth ed. Strasbourg: Council of Europe; 2016. p. 2254-5.

7. International Conference on Harmonisation. Stability Testing of New Drug Substances and Products Q1A(R2), (2003).

8. Maheswaran R. FDA Perspectives: Scientific Considerations of Forced Degradation Studies in ANDA Submissions. Pharmaceutical Technology. 2012; 36(5):73-80.

9. Chakole RD, Charde MS, Kumar J, Welankiwar AS. Development of forced degradation studies of drugs. International Journal of Advances in Pharmaceutics. 2013; 2(3): 34-39.

10. Singh $\mathrm{S}$, Bakshi M. Stress test to determine inherent stability of drugs. Pharm Technol. 2000; 4:1-14.

11. Klick S, Pim GM, Waterval J, et al. Toward a Generic Approach for Stress Testing of Drug Substances and Drug Products. Pharm Technol. 2005; 29(2):48-66.

12. Alsante KM, Martin L, Baertschi SW. A Stress Testing Benchmarking Study. Pharmaceutical Technology. 2003, 27(2): 60-72.

13. Sonawane S, Gide P. An experimental design approach for the forced degradation studies and development of a stability-indicating LC method for eplerenone in tablets. J Liq Chromatogr Relat Technol. 2011; 34:2020-2031.
14. Singh S, Modhe G, Tiwari H, Kurmi M, Parashar N, Sidduri $P$. Forced degradation studies to assess the stability of drugs and products. Trends Anal Chem. 2013; 49:71-88.

15. Sonawane S, Gide P. Optimization of forced degradation using experimental design and development of a stabilityindicating liquid chromatographic assay method for rebamipide in bulk and tablet dosage form. Sci Pharm 2011; 79(1): 85-96.

16. Raijada DK, Prasad B, Paudel A, Shah RP, Singh S. Characterization of degradation products of amorphous and polymorphic forms of clopidogrel bisulphate under solid state stress conditions. J Pharm Biomed Anal. 2010; 52(3):33244.

17. Kurmi M, Kumar S, Singh B, Singh S. Implementation of design of experiments for optimization of forced degradation conditions and development of a stability-indicating method for furosemide. Journal of Pharmaceutical and Biomedical Analysis. 2014; 96:135-43.

18. Dan W. Reynolds BKJ. Stresss testing of combination therapies. In: Baertschi SW, Alsante KM, Reed RA, editor. Pharmaceutical Stress Testing: Predicting Drug Degradation. Second ed. London: Informa Health; 2011. p. 448-55.

19. Kurmi M, Golla VM, Kumar S, Sahu A, Singh S. Stability behaviour of antiretroviral drugs and their combinations. 1: characterization of tenofovir disoproxil fumarate degradation products by mass spectrometry. RSC Advances. 2015; 5(116):96117-29.

20. Snyder LR, Kirkland JJ, Glajch JL. Practical HPLC Method Development. Second ed. USA: John Wiley \& Sons; 1997.

21. Shah P, Patel J, Patel K, Gandhi T. Development and validation of an HPTLC method for the simultaneous estimation of clonazepam and paroxetine hydrochloride using a DOE approach. J Taibah Uni Sci. 2017; 11:121-32.

22. Bajaj M, Nanda S. Analytical quality by design (AQbD): new paradigm for analytical method development. Int J Dev Res. 2015; 5:3289-599.

23. Gholve SB, Ajgunde RR, Bhusnure OG, Thonte SS. Analytical method development and validation by QbD approach - a review. Der Pharmacia Sinica. 2015; 6:18-24

24. Beg S, Sharma G, Katare OP, Shikha L, Singh B. Development and validation of a stability indicating liquid chromatographic method for estimating olmesartan medoxomil using quality by design. J Chromatogr Sci. 2015; 53:1048-59.

25. Kumar L Reddy MS, Managuli RS, Pai KG. Full factorial design for optimization, development and validation of HPLC method to determine valsartan in nanoparticles. Saudi Pharm J. 2015; 23:549- 55.

26. Food and Drug Administration International Conference on Harmonisation. Guidance on Q11 Development and Manufacture of Drug Substances; availability. Notice. Fed. Regist. 2012; 77:69634-69635.

27. N Politis S, Colombo P, Colombo G, M Rekkas D. Design of experiments (DoE) in pharmaceutical development. Drug Development and Industrial Pharmacy 2017; 43(6):889-901.

28. Abelson J, Simon M. Biothiols Part A Monothiols and Dithiols, Protein Thiols, and Thiyl Radicals. Academic Press, 1995.

29. Ullmann's Encyclopedia of Industrial Chemistry. 7 ed. Germany: Wiley-VCH Verlag GmbH \& Co, 2005. 